\title{
A Review of Mobile Robot Navigation System for Volcano Monitoring Application
}

\author{
Maria Evita $^{1^{*}}$, Mitra Djamal $^{1}$ \\ ${ }^{1}$ Department of Physics, Faculty of Mathematics and Natural Sciences, Jalan Ganesha No. 10, Bandung 40116, \\ Indonesia
}

( Received: January 21,2021, Revised: October 10, 2021, Accepted: November 5, 2021 )

\begin{abstract}
Volcano is a geological environment including magma, eruption, volcanic edifice and its basements. For continuous monitoring after eruption, a mobile robot could be proposed as an alternative to prevent hazardous effect to volcanologist who perform up close monitoring. In this paper, the robots were divided into 3 types according to their different structures: legged, track-legged and wheeled mobile robots. Meanwhile, the navigation system were implemented in 4 steps suitable for volcano condition: environment mapping, trajectory design, motion control and obstacle avoidance. These navigation system also tested in different locations: indoor, outdoor and real volcano with different testing method for these robots. The testing result was discussed in robot kinematics parameter such as trajectory, velocity, slope angle, rollover and sideslip angels.
\end{abstract}

Keywords: mobile-robot, volcano, monitoring-system, navigation, control.

\section{INTRODUCTION}

Volcano is a highly complex geological dynamic environtment (not only an igneous system from the deepest root up to the surface), where all kinds of geologic process act on the rising magma, the eruptions, the volcanic edifice and its basement [1], [2]. There are more than 500 active volcanoes of about 1000 of volcanoes all over the world which fit with that definition [3]. It is needed a volcano monitoring sytem at each one of these volcanoes (at least for eaethquake, release of magnetic gases and surface deformation [4]) to reduce this natural disaster's risk [5]. Some unconventional system have been developed to overcome problems occure during the monitoring process [6], [7], [8], [9], [10], [11], [12]. However, during or after the eruption, the system may be broken and the hazard environment could be dangerous for volcanologist to fix the system while a continuous observation still be needed at the same time [13], [14].

Mobile robot technology could be the alternative solution in this situation (Fig. 1). Dante II, a legged robot for volcano exploration has been developed by NASA and Carnegie Melon University

in 1999 [15]. Few years later, European Commission introduced their giant mobile robot called Robovolc for volcano observation [14]. Nagatani also reported his work about a novel multi-D.O.F. tracked vehicle, called ELF, which can conduct observation in a restricted volcanic area [16], [17]. Furthermore, there are some other robot for different exploration such as Artemis [18] and Merlin [19] for heterogenus surface and uneven terrain applications with suitable navigation system. Hence, the navigation and control system of the mobile robot should be able to detect and aboid hazard zone as well as generate path planning to specific target (s) [16], [17], [20], [21].

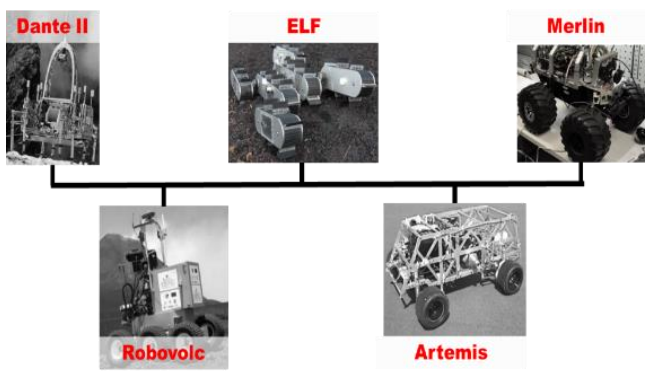

*Corresponding author.

E-mail address: maria@fi.itb.ac.id 
Fig. 1. Mobile robot for volcano monitoring

This review will discuss about navigation system integrated with its control system for volcano monitoring application, the test, the test result and discussion and final remark for the system explained. The robot will be divided into 3 types according to their different structurus: legged, track-legged and wheeled mobile robots. Therefore, students who needs information about navigation system of mobile robots for volcano monitoring application could utilize the information.

\section{NAVIGATION SYSTEM}

Mobile robot navigation is the ability of a mobile robot to get from one place to another (destination) in an orderly manner required by the job, volcano monitoring for this case. This system can be divided into four steps: environment mapping, trajectory design, motion control and obstacle avoidance [22], [23]. To construct environment map, a mobile robot should be equipped with a proper vision system. Whereas for trajectory design, it is needed an inertial navigation to track the position and orientation of the object [24], to control the robot motion while avoiding obstacle(s) [25].

\section{(1) Legged mobile robot.}

Environtment mapping process is crucial for a legged mobile robot (such Dante II) to avoid obstacle or slip off precarious footholds by adapting to actual condition through continuously relating sensation to action this behavior-based architectures walking robot. Dante II - an eight-legged mobile robot - uses UI3D (a three-dimensional visualization and its surrounding terrain) and [15] VEVI (Virtual Environtment Vehicle Interface, a modular operator interface for robotic vehicles) to generate local elevation map and to utilize real-time, interactive, 3D graphic and feedback from onboard sensors [15], [26] (Fig. 2).

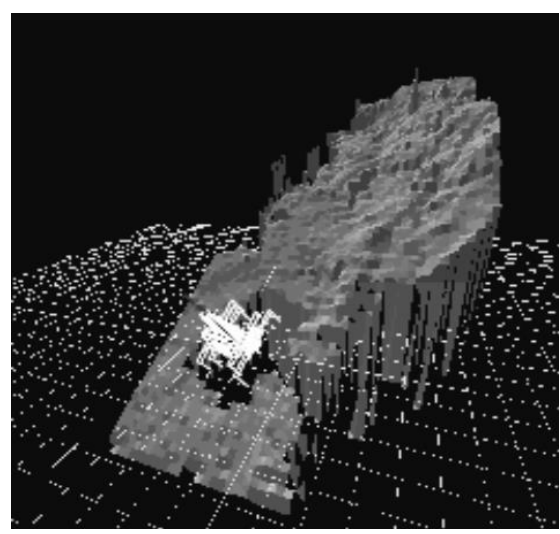

Fig. 2. Environment 3D mapping of Dante II [15]

Determining the most effective parameterization of the gait behaviors by collection of individual planners is suitable trajectory planning for Dante II [15], [27], [28], [29]. This gait behavior (in Dante II has 24 asynchronous process: eight contact-foot behaviors to stand, eight freefoot behaviors to step, one each of raise-legs, moveframe, turn-frame, lower-legs, and sit-still behaviors to walk, and roll, pitch, and clearance behaviors to posture) together with control process, allows the foot to move, halt or reflex to some environment condition (vertical or horizontal terrain) e.g if it loses contact with the ground [15], [30], [31].

The gait-control process run in onboard processor. Furthermore, this real-time control motion (in one or more processor(s)) collects sensor information, write the state into shared memory, drive the eg PD servo loops, service for translation, turn and tether actuators [15], [30], [31].

This motion control also responsible for obstacle-crossing capability by the free-foot behavior [15], [30], [31]. Shortly after the robot detect obstacle, the legs raise up in coordination with a momentary pause in body motion [15], [32], [33], [34].

\section{(2) Track-legged mobile robot.}

Generlly, there is no environment mapping for a track-legged mobile robot such ELF (specially made for weak and uneven terrain of volcano). It is because its robust locomotion performance to explore different terrain and texture as well as "climbing" the obstacles [16], [17], [35]. However, trajectory planning is designed as simple as possible, hence the robot should only move in a straight desired path to the destination [16], [17], [35].

To reduce downhill slide slip in volcano area, the robot poster should be controlled verticaly to gravity [16], [36], [37]. Moreover, an orientation controller is added for the transversal motion by creating a gap in the locomotion velocities of both main tracks [16], [36], [37]. This main tracks and 4subtracks coordinate for entire robot motion commanded by a control unit via wireless LAN [16], [36], [37] (Fig. 3). 


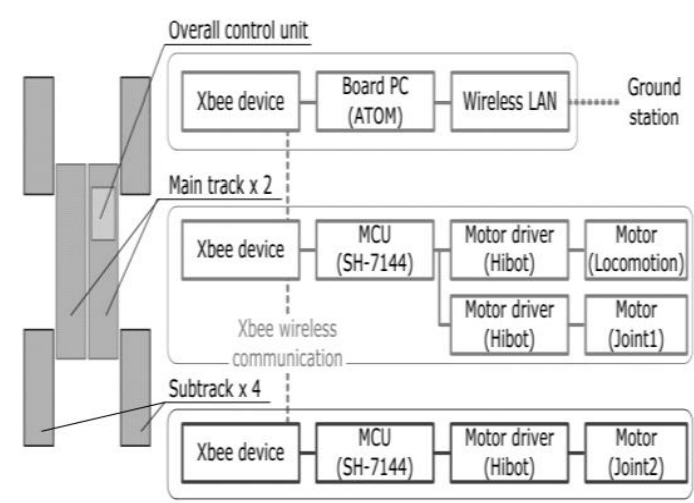

Fig. 3. Configuration of ELF's controller (adapted from [16])

\section{(3) Wheeled mobile robot.}

The navigation system for wheeled mobile robot usually implemented into four layers: long range planning, short range planning, instant path planning and control motion as we can find in Robovolc, Artemis and Merlin [14], [18], [19], [38]. Long range planning is the layer for generating an environment map base on waypoints built by sensor input from fixed cameras (5 cameras including IR camera in Robovolc), ultrasonic sensors etc. [14], [38]. Short range [14], [18], [19], [39], [40] and instant path plannings [14], [18], [19], [41] are responsible for trajectory planning process to manage the navigation between the waypoints and decide the direction of the robot. Furthermore, the motion control layer transforms this plans into control commands for motion control boards [14], [18], [19], [42], [43], [44], [45].

In Robovolc, a localization system to determine the exact location of the robot has been performed in two ways: Self Kalibrating Extended Kalman Filter (EKFSC) and orientation estimator [14]. Moreover, the obstacle avoidance is teleoperated by volcanologist through the vision of its cameras [14].

On the other side, ARTEMIS a 4 wheeled mobile robot as Merlin, concludes the four steps of navigation system in one algorithm.

A high-level control layer generated some waypoints as the mobile robot optimal trajectory [46]. On the other side, the low- level layer navigated robot through this trajectory via potential field [46] an elegant hybrid method both for reactive and deliberative behavior of its environment [19] which can deal with complex obstacles [19] as well as controlled to the desired point. To control optimal trajectory, it was performed a look-a-head model for navigating the mobile robot without failures [46] through checking the collision with its environment [19].
The algorithm for this method is as followed:

1. The value of the net potential field at the robot's current position in trajectory space (TS) is calculated from Eq. (1). Position in TS is a curvature-velocity $(\kappa, \mathrm{V}) \quad$ pair [46].

$P F(v, \kappa)=P F_{r}(v, \kappa)+P F_{s}(v, \kappa)+P F_{g}(\kappa)+P F_{v}(v)+\sum_{i=1}^{n} P F_{0}^{i}(v, \kappa)$

Where, $P F_{r}(v, \kappa)$ is potential field for rollover constraint, $P F_{s}(v, \kappa)$ is potential field for side slip constraint, $P F_{g}(\kappa)$ is potential field for corresponding to the current desired waypoint location, $P F_{v}(v)$ is potential field for desired velocity, and $\sum_{i=1}^{n} P F_{0}^{i}(v, \kappa)$ is potential field for hazard locations (including other obstacles) [46].

2. The gradient of the net potential field is computed, and a desired maneuver (i.e. a $(\mathrm{v}, \mathrm{\kappa})$ pair) is chosen in the direction of maximum descent [46].

3. The predicted trajectory of the robot is computed via forward simulation of a rigid body model (Fig. 4) subject to the desired maneuver over time dt, where $F$ is the sum of all the horizontal tire forces, $\mathrm{R}$ the sum of all normal tire forces, and the weight is mg [46].

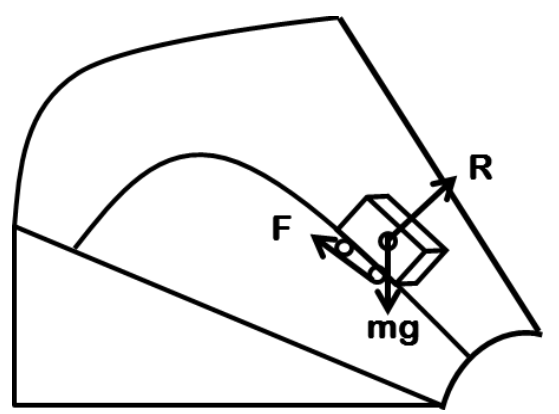

Fig. 4 Rigid body model for mobile robot simulation (adapted from [46])

4. Steps 1-3 are repeated while t (virtual time in a forward simulation loop) is no more than $\mathrm{T}$ [46].

5. A maximum safe velocity profile is computed over the predicted path. Maximum safe velocity profile was defined from the cost function $J=\int_{s_{1}}^{s_{2}} \frac{d s}{\dot{s}_{m}}$, where $J$ is cost function (time), $d s$ path arc length, $\dot{S}_{m}$ maximum safe speed [46]. 
6. The predicted robot velocity profile is compared to the maximum safe velocity profile [46]. Robot velocity profile $\dot{s}$ is the solution from $\mathrm{Eq}(2),(3)$, and (4)

$$
\begin{aligned}
& f_{t}=m g k_{t}+m \ddot{s} \\
& f_{q}=m g k_{q}+m \kappa n_{q} \dot{s}^{2} \\
& R=m g k_{r}+m \kappa n_{r} \dot{s}^{2}
\end{aligned}
$$

where $f_{t}$ and $f_{q}$ are components of the friction force tangent and normal to the path, $\kappa$ the path curvature, $\mathrm{k}$ is a unit vector pointing opposite of the gravity force, $\mathrm{n}$ is a unit vector pointing in the direction of the path center of curvature, and the subscripts denote projections along the path coordinate frame, $\mathrm{t}, \mathrm{q}, \mathrm{r}$.

If the predicted velocity profile exceeds the maximum safe velocity profile at any point, the robot's desired velocity is reduced to the maximum safe velocity along the trajectory.

The navigation system for these mobile robot

\begin{tabular}{|c|c|c|c|}
\hline & \multicolumn{3}{|c|}{-Mobile Robot } \\
\hline & Legged- & $\begin{array}{l}\text { Track- } \\
\text { legged- }\end{array}$ & Wheeled- \\
\hline $\begin{array}{c}\text { Environment } \\
\text { Mapping }\end{array}$ & UI3D-VEVI & - & $\begin{array}{l}\text { Long range } \\
\text { planning, } \\
\text { waypoints- } \\
\text { potential } \\
\text { field }\end{array}$ \\
\hline $\begin{array}{l}\text { Trajectory } \\
\text { Design }\end{array}$ & $\begin{array}{c}\text { Gait } \\
\text { behaviours }\end{array}$ & $\begin{array}{l}\text { Move in } \\
\text { straight } \\
\text { path }\end{array}$ & $\begin{array}{c}\text { Short range } \\
\text { planning, } \\
\text { look-a-head } \\
\text { model }\end{array}$ \\
\hline $\begin{array}{l}\text { Motion } \\
\text { Control }\end{array}$ & Gait-control & $\begin{array}{c}\text { Robot } \\
\text { poster } \\
\text { controlled } \\
\text { vertically, } \\
\text { orientation } \\
\text { controller } \\
\quad \text { for } \\
\text { transversal } \\
\text { motion } \\
\end{array}$ & $\begin{array}{c}\text { Motion } \\
\text { control } \\
\text { layer }\end{array}$ \\
\hline $\begin{array}{c}\text { Obstacle } \\
\text { avoidance }\end{array}$ & $\begin{array}{l}\text { Free-foot } \\
\text { behaviour }\end{array}$ & - & $\begin{array}{c}\text { Camera } \\
\text { vision, look- } \\
\text { a-head } \\
\text { model }\end{array}$ \\
\hline
\end{tabular}
could be conclude in Table 1.

Table 1. Camparison of mobile robot navigation system

\section{TESTING METHOD}

The navigation system of a mobile robot should be tested to meet the design requirement before it is used frequently and repeteadly [47]. The different testing method for 3 different kind of robots will be explain here.

\section{(1) Legged mobile robot.}

Flat-floor walking was the first test for a legged mobile robot, Dante II including body translation, turning [48], maximum body lifts [49], [50], and coordinated winch operation [15], [51]. The next test is walk on a $30^{\circ}, 7-\mathrm{m}$-long ramp while maintaining a gravity-balancing tension on the tether cable including walking, turning, and obstaclecrossing capabilities [15], [52], [53].

For outdor testing, the robot was tested on a hillside [15], [54], [55], [56]. The path included a 10$\mathrm{m}$ steep slope $\left(50^{\circ}\right)$ followed by a $5-\mathrm{m}$ flat area, which transitioned into a 30-m variable-slope region (20$\left.50^{\circ}\right)$ to the top. The path also included some minor (about $10^{\circ}$ ) cross-slopes [15], [57], [58], [59]. The terrain was hard soil covered with light vegetation [15]. Furthermore, the mixed-terrain testing was held on a $5-\mathrm{m}$ flat section of the path covered with large boulders $(0.5-1-\mathrm{m}$ tall) in an effort to emulate the worst-case conditions expected [15], [60].

Dante II was also tested on full-scale volcanolike terrain [15], [61], [62]. Some test were conducted along a $170-\mathrm{m}$ path. The upper portion of the path is level for $40 \mathrm{~m}$, and then slopes into a smooth escarpment of $30-40^{\circ}$ for $70 \mathrm{~m}$ and $40-50^{\circ}$ for $5 \mathrm{~m}$, and then follows a moderate but trenched uphill grade for $60 \mathrm{~m}$ [15].

The final destination for robot teting was a real volcano. Dante II was tested on Mout Spurr, Alaska which consisted of three segments: descent to the crater floor, floor exploration, and ascent [15].

\section{(2) Track-legged mobile robot.}

One of the greatest challenges is downhill sideslip often found in volcano. To reduce this slip, ELF was controlled to remain vertical with respect to gravity by a mechanical model based on terramechanics theory for the robot which has the capability of swinging its subtracks while maintaining its attitude [16], [63], [64], [65], [66]. 
An indoor testing in a simulated volcanic field [67] with $3 \mathrm{~m}$ and $1 \mathrm{~m}$ of length and width respectively with pumice stones whose bulk density was less than that found in actual volcanic fields, has been performed to confirm the effectiveness of the controller in navigation system [16]. The test was held in $30^{\circ}$ of $5^{\circ}$ interval of slope angle where for each angle two configurations of the robot-normal contact and horizontal contact were examined, and three trials were conducted using the same configuration at $8 \mathrm{~cm} / \mathrm{s}$ of velocity [16]. The slip angle $(\beta)$ on the slope [68], [69] was evaluated using Eq. 5 [16].

$$
\beta=\tan ^{-1} \frac{v_{y}}{v_{x}}
$$

where $v_{x}$ denotes the locomotion velocity of the robot and $\mathrm{v}_{\mathrm{y}}$ denotes the sideslip velocity.

The test also conducted on a real volano of Mount Kushigata where the slope (about $30^{\circ}$ ) was covered by scoria (weak soil) with $12 \mathrm{~cm} / \mathrm{s}$ of velocity and $10 \mathrm{~m}$ navigation distance in two configurations as well [16]. The robot's trajectory was recorded by the surveying equipment [16].

\section{(3) Wheeled mobile robot}

The robot parameter for odometry [70], [71], [72], [73], [74] of Robovolc was as follow: wheels radius: $\mathrm{R}_{1}=0.21 \mathrm{~m}, \mathrm{R}_{2}=0.21 \mathrm{~m}$, wheelbase: $\mathrm{L}=$ 0.82m, while for EKF algorithm [75], [76], [77], [78], [79] was used DGPS [14], [80]. Meanwhile, ARTEMIS $0.89 \times 0.61 \times 0.38 \mathrm{~m}$ of dimension, which has $700 \mathrm{MHz}$ Pentium III PC -104 onboard computer, Crossbow AHRS-400 INS, a tachometer to measure wheel angular velocity, $20 \mathrm{~cm}$ resolution DGPS, and Futaba steering and throttle control servos, was tested on a flat, bumpy terrain covered with grass [46]. To study an obstacle avoidance [81], [82], an obstacle of $1 \mathrm{~m}$ radius was set at $(\mathrm{x}, \mathrm{y})=(15.0,0.0)$ and $\mathrm{a}$ waypoint was set at $(\mathrm{x}, \mathrm{y})=(30.0,0.0)$. The desired velocity was set at $4.0 \mathrm{~m} / \mathrm{s}$. Note that for a vehicle of this size, rollover [63], [83] can easily occur at 4.0 $\mathrm{m} / \mathrm{s}[46]$.
The three different testing method are concluded in Table 2.

Table 2. Testing method for navigation system of mobile robots

\begin{tabular}{|c|c|c|c|}
\hline & \multicolumn{3}{|c|}{-Mobile Robot } \\
\hline & Legged- & Track-legged- & Wheeled \\
\hline Indoor & $\begin{array}{l}\text { Flat-floor } \\
\text { walking } \\
\text { (body } \\
\text { translation, } \\
\text { turning, } \\
\text { maximum } \\
\text { body lifts, } \\
\text { and } \\
\text { coordinated } \\
\text { winch } \\
\text { operation), } \\
\text { walking on a } \\
\text { ramp } \\
\text { (walking, } \\
\text { turning, and } \\
\text { obstacle- } \\
\text { crossing } \\
\text { capabilities) }\end{array}$ & $\begin{array}{l}\text { In a simulated } \\
\text { volcanic field } \\
\text { with pumice } \\
\text { stones in a hill } \\
\text { surface } \\
\text { (mechanical } \\
\text { model based } \\
\text { on } \\
\text { terramechanics } \\
\text { theory): slip } \\
\text { angle }\end{array}$ & $\begin{array}{c}\text { on a flat, } \\
\text { bumpy } \\
\text { terrain } \\
\text { covered } \\
\text { with grass: } \\
\text { waypoints } \\
\text { and } \\
\text { obstacle } \\
\text { avoidance. }\end{array}$ \\
\hline Outdoor & $\begin{array}{l}\text { On a hillside } \\
\text { with different } \\
\text { slopes on } \\
\text { hard soil } \\
\text { covered with } \\
\text { light } \\
\text { vegetarian, } \\
\text { on a } \\
\text { volcanolike } \\
\text { terrain }\end{array}$ & - & - \\
\hline $\begin{array}{c}\text { Real } \\
\text { Volcano }\end{array}$ & $\begin{array}{l}\text { At Mount } \\
\text { Spurr: the } \\
\text { crater floor, } \\
\text { floor } \\
\text { exploration, } \\
\text { and ascent }\end{array}$ & $\begin{array}{l}\text { At Mount } \\
\text { Kushigata: } \\
\text { slopes covered } \\
\text { by scoria: } \\
\text { robot } \\
\text { trajectory }\end{array}$ & $\begin{array}{l}\text { At Mount } \\
\text { Etnaa: } \\
\text { odometry } \\
\text { and DGPS }\end{array}$ \\
\hline
\end{tabular}




\section{RESULTS AND DISCUSSION}

Some parameters usually discuss in mobile robot navigation system are: trajectory [23], [84], [85], [86], velocity and angles [87] (rollover, sideslip, slope). In this section the testing result will be discuss regarding these parameters.

\section{(1) Legged mobile robot.}

Flat-floor walking testing efficiently conducted without major problem as well as on a ramp testing and a hillside beside a building [15]. The robot was set to far away from the user as well as communication bandwidth limitation in extremely hot weather and rain as actual mission later [15], [88]. The robot could provide terrain information through its cameras and scanning-laser range finder [15]. In a hillside location, the robot run for 182 steps over $111 \mathrm{~m}$ in $219 \mathrm{~min}$ for an average speed of $0.51 \mathrm{~m} / \mathrm{min}$, where the roll and pitch were maintained to within $\pm 2^{\circ}$ [15]. The free-foot reflex was effectively implemented where the feet could skim the ground, providing protection against tipping, and raise up if they bumped [15]. The mission was conducted in over 30 hour period where the vision system could work properly [15]. However, the behavior required only $179 \min$ (2:59) with the gait controller averaged $0.51 \mathrm{~m} / \mathrm{min}$, and in some areas averaged $0.67 \mathrm{~m} / \mathrm{min}$ [15].

Mount Spurr is the final desination for Dante II where has a crater that could no be entered by volcanologist [89] which has cross slope up to $30^{\circ}$ with $23.3 \mathrm{~min}(0.42 \mathrm{~m} / \mathrm{min})$ of autonomous walking for $9.8 \mathrm{~m} \mathrm{[15].} \mathrm{After} \mathrm{the} \mathrm{robot} \mathrm{facing} \mathrm{a} \mathrm{dead} \mathrm{end,}$ Dante II turned around and made two autonomous descents down in $35.2 \mathrm{~min}(0.24 \mathrm{~m} / \mathrm{min})$ for $8.3 \mathrm{~m}$ and $12.3 \mathrm{~min}(0.49 \mathrm{~m} / \mathrm{min})$ for $6 \mathrm{~m} \mathrm{[15]}$. The laserbuilt 3-D elevation maps have been successfully generated and used during the exploration [15]. However, the laser scanner had become obscured by airborne volcanic ash [15]. Therefore, the vision only obtained by the cameras [15]. The communication and power have lost during the escent exploration because of a moisture-related short circuit in the power cabling at the rim [15]. Moreover, it also fell (on the side) due to a combination of factors including steep slope and cross-slope conditions, soft unstable slope material, a destabilizing tether-exit angle, and a control algorithm that had never been tested in such perilous stability conditions [15].

\section{(2) Track-legged mobile robot.}

From the test result, it could be explained that the contact plane should be set horizontally when traversing a weak slope, which caused the tracks should be configure to adapt to the target slope angle for up to $25^{\circ}$ [16]. Therefore, an orientation control has been applied by creating a gap in locomotion velocities $\mathrm{v}_{1}$ and $\mathrm{v}_{\mathrm{r}}$ by Eq. 6 and 7 [16].

$$
\begin{aligned}
& v_{l}=v+c \varphi \\
& v_{r}=v-c \varphi
\end{aligned}
$$

where $\mathrm{v}$ is velocity, $\mathrm{c}$ is coefficient vaue and $\varphi$ is yaw angle obtained by the IMU [16], [70], [90], [91].

Moreover, according to its 3D-trajectory it is shown that the robot generated a higher degree of sideslip than it did with the horizontal contact configuration, with $2.7 \mathrm{~m}$ deviation from desired path at point $7 \mathrm{~m}$, then be reduced in horizontal configuration by $58 \%$ which could make the robot survive in a weak slope where the controller contributes to the suppression of its trajectory [16]. However, the slideslip stoped when the orientation of robot became $-15^{\circ}$. It could change in a downhill at any time where slidesip occure contonously in angle of $30^{\circ}$ of normal contact configuration where the robot could not change the orientation because it dug into the ground [16]. The slip angle in the horizontal contact configuration was less than half of the angle in the normal configuration where a small degree of slideslip occurred in $10^{\circ}$ slope angle [16].

\section{(3) Wheeled mobile robot.}

The odometry parameters could be estimated when the robot (Robovolc) moving along the trajectory: $\mathrm{R}_{1}(\mathrm{t}=90)=0.209 \mathrm{~m}, \mathrm{R}_{2}(\mathrm{t}=90)=0.208 \mathrm{~m}$ of wheel radiuses and $\mathrm{L}(\mathrm{t}=90)=0.816 \mathrm{~m}$ of wheel base in a real volcano of Mount Etna [14], [92]. EKFSC method showed satisfy result which reconstruct the trajectory which very close to the real one, and better than others method (EKFClasic and EKF calibrated via UMBmark) with average speed of $0.81 \mathrm{~m} / \mathrm{s}$ [14].

Furthermore, a car-like mobile robot such as Merlin and ARTEMIS have shown significant results for the navigation system from the testing inside laboratory. An obstacle has been successfully avoided and the waypoints have also been reached. GPS offset result in an nitial heading error. The velocity was controlled to decreas at a large curvature to avoid the obstacle (i.e. around $\mathrm{x}=15.0 \mathrm{~m}$ ) near 4 $\mathrm{m} / \mathrm{s}$ in save region (i.e. after $\mathrm{x}=25.0 \mathrm{~m}$ ) without rollover and slideslip. Moreover, the testing with 3 waypoints has also succecessful result where the robot navigated to and reached the waypoints where velocity was controlled near $4 \mathrm{~m} / \mathrm{s}$ in save region and also decrease at large curvature. 
These results are concluded in Table 3.

Table 3. Result testing of mobile robots

\begin{tabular}{|c|c|c|c|}
\hline & \multicolumn{3}{|c|}{-Mobile Robot } \\
\hline & Legged- & $\begin{array}{l}\text { Track- } \\
\text { legged- }\end{array}$ & Wheeled \\
\hline Trajectory & $\begin{array}{l}\text { Following } \\
\text { the path of } \\
\text { 3D } \\
\text { elevation } \\
\text { map }\end{array}$ & $\begin{array}{l}\text { Generated } \\
\text { higher degree } \\
\text { of sideslip }\end{array}$ & $\begin{array}{l}\text { Following } \\
\text { the } \\
\text { waypoints } \\
\text { generated } \\
\text { by high } \\
\text { level } \\
\text { planner, } \\
\text { odometry }\end{array}$ \\
\hline Velocity & $\begin{array}{c}\text { Varied } \\
\text { (under } 0.6 \\
\mathrm{~m} / \mathrm{min} \text { ) } \\
\text { according } \\
\text { to the slope }\end{array}$ & $8 \mathrm{~cm} / \mathrm{s}$ & $\begin{array}{c}0.81 \mathrm{~m} / \mathrm{s} \\
\text { (average } \\
\text { speed for } \\
\text { Robovolc), } \\
\text { controlled } \\
\text { near } 4 \mathrm{~m} / \mathrm{s} \\
\text { or uder in a } \\
\text { large } \\
\text { curvature } \\
\text { (ARTEMIS) }\end{array}$ \\
\hline Slope & Up to $30^{\circ}$ & Up to $30^{\circ}$ & Up to $30^{\circ}$ \\
\hline Rollover/Fell & $\begin{array}{l}\text { Fell on the } \\
\text { side }\end{array}$ & - & - \\
\hline Sideslip & - & $\begin{array}{c}\text { Occure } \\
\text { continuously } \\
\text { at } 30^{\circ} \text { of } \\
\text { normal } \\
\text { contact } \\
\text { configuration, } \\
\text { stoped when } \\
\text { the } \\
\text { orientation of } \\
\text { robot became } \\
-15^{\circ}, \text { in } \\
\text { horizontal } \\
\text { contact } \\
\text { configuration: } \\
10^{\circ}\end{array}$ & - \\
\hline
\end{tabular}

\section{CONCLUSION}

To prevent the hazard for volcanologist during volcano monitoring, there have been developed mobile robots for monitoring of volcanoes. Volcano is a challenging environment to be explored. Therefore, the robot should be equipped with a proper navigation system. Thede robot were divided into 3 types: legged, track-legged and wheeled mobile robots which have 4 steps of navigation system: environment mapping, trajectory design, motion control and obstacle avoidance. Legged mobile robot concerned in its gait behavior, while tracked-mobile robot on its motion control with no step of obstacle avoidance, and wheel mobile robot more concerned about rollover and slide lip angles. The navigations sytems have been tested in indoor, aoutdoor and real volcano and discussed in some parameters: trajectory, velocity and angles. These robots have been autonomously move along trajectory generated by high level planner through 3D map generation, slideslips data, waypoints and odometry parameters while moving in controlled velocity under $4 \mathrm{~m} / \mathrm{s}$ (the fastest) on a slope up to $30^{\circ}$. There was no rollover experienced by the robots, except for the legged robot which fell on its side during walking on the slope. Sideslips only occured continuously in track-legged mobile robot at $30^{\circ}$ of normal contact configuration and $10^{\circ}$ in horizontal contact configuration.

\section{ACKNOWLEDGMENT}

I would like to thank you to Prof. Suprijadi for the input and discussion especially in Introduction and Method sections.

\section{REFERENCES}

[1] A. Borgia et al., What is a volcano?, The Geological Society of America, 470, 1, 2010.

[2] A. Szakacs, From a definition of volcano to conceptual volcanology, The Geological Society of America, 470, 67, 2010.

[3] C. J. Farnley et al., Observing the Volcano World, Springer, Cham, 1, 2017.

[4] R. S. J. Sparks, J. Biggs, and J. W. Neuberg, Monitoring Volcanoes, Science, 335, 1310, 2012.

[5] R. I. Tilling, The critical role of volcano monitoring in risk reduction, $A d v$. Geosci., 14, 3, 2008.

[6] R. L. Cueva et al., Performance Evaluation of a Volcano Monitoring System Using Wireless Sensor Networks, IEEE, 2014.

[7] R. Tan et al., Fusion-based Volcanic Earthquake Detection and Timing in Wireless Sensor Networks, ACM Transactions on Sensor Networks, V, 1, 2014. [8] J. Biggs et al., Global link between deformation and volcanic eruption quantified by satellite imagery, Nature Communications, 5, 3471, 2014.

[9] S. H. Chio, and C. H. Lin, Preliminary Study of UAS Equipped with Thermal Camera for Volcanic Geothermal Monitoring in Taiwan, Sensor, 17, 1649, 2017.

[10] Surono et al., The 2010 explosive eruption of Java's Merapi volcano-A '100-year' event, Journal of Volcanology and Geothermal Research, 241, 121, 2012.

[11] A. E. Hassanien et al. (eds.), Pervasive Computing: Innovations in Intelligent Multimedia and Applications, Computer Communications and Networks, Springer-Verlag London Limited, London, 201, 2009.

[12] R.S. Matza et al., Volcano infrasound and the International Monitoring System, California Digital Library, California, 1023, 2019. 
[13] K. Nagatani et al., Development and Field Test of Teleoperated Mobile Robots for Active Volcano Observation. International Conference on Intelligent Robots and Systems (Chicago), 2014.

[14] D. Caltabiano, and G. Muscato, A Robotic System for Volcano Exploration, Cutting Edge Robotics, Advance Robotic Systems Scientific Book, 499, 2005.

[15] J. E. Bares, and D. S. Wettergreen, Dante II: Technical Description, Results, and Lessons Learned, The International Journal of Robotics Research, 18, 621, 1999.

[16] K. Nagatani, T. Noyori, and K. Yoshida, Development of Multi-D.O.F. Tracked Vehicle to Traverse Weak Slope and Climb up Rough Slope, International Conference on Intelligent Robots and Systems, 2013.

[17] K. Nagatani et al., Development of leg-track hybrid locomotion to traverse loose slopes and irregular terrain, International Conference on Intelligent Robots and Systems, 2011.

[18] S. Shimoda, Y. Kuroda, and K. Iagnemma, Potential Field Navigation of High Speed Unmanned Ground Vehicles on Uneven Terrain, International Conference on Robotics and Automation (April, 2005, Barcelona) IEEE, 2828, 2005.

[19] R. Hess, F. Kempf, and K. Schilling, Trajectory Planning for Car-Like Robots using Rapidly Exploring Random Trees, 3rd IFAC Symposium on Telematics Applications (November 11-13, 2013. Seoul), 44, 2013.

[20] Z. Xu et al., Formation control of car-like autonomous vehicles under communication delay, Control Conference, (Chinese, 2012), 6376, 2012.

[21] T. Lindeholz et al., Asymptotic optimal trajectory planning under consideration of kinematic and direction constraints for mobile car-like robots, 47st International Symposium on Robotics, (2016, Munich, 1, 2016.

[22] T. T. Hoan et al., Proposal of Algorithms for Navigation and Obstacles Avoidance of Autonomous Mobile Robot, 2013 IEEE 8th Conference on Industrial Electronics and Applications (ICIEA), (2013, Melbourne), 1308, 2013.

[23] J. Velagic, B. Lacevic, and B. Perunicic, A 3level autonomous mobile robot navigation system designed by using reasoning/search approaches, Robotics and Autonomous Systems, 54, 989, 2006.

[24] M. E. Qazizada, and E. Pivarčiová, Mobile robot controlling possibilities of inertial navigation system, International Conference on Manufacturing Engineering and Materials, (June, 6-10, 2016, Nový Smokovec), vol 149, (Amsterdam: NorthHolland/American Elsevier), 404, 2016.
[25] L. McFetridge, and M.Y. Ibrahim, A new methodology of mobile robot navigation: The agoraphilic algorithm, Robotics and ComputerIntegrated Manufacturing, 25, 54, 2009.

[26] B. Hine et al., VEVI: A Virtual Environment Teleoperations Interface for Planetary Exploration, SAE 25th International Conference on Environmental Systems, (July, 1995, San Diego), 1995.

[27] Q. Zeng et al., Leg Trajectory Planning for Quadruped Robots with High-Speed Trot Gait, Appl. Sci., 9, 1508, 2019.

[28] L. Gagliardini L. et al., Modelling and Trajectory Planning for a Four Legged Walking Robot with High Payload, Notes in Computer Science, 7621, 2012.

[29] K. Hauser et al., Motion Planning for Legged Robots on Varied Terrain, The International Journal of Robotics Research, 27, 1325, 2008.

[30] D. Wettergreen, and C. Thorpe, Gait Generation for Legged Robots, International Conference on Intelligent Robots and Systems, (July, 1992) IEEE, 1992.

[31] P. M. Khrisna, R. P. Kumar, and S. Srivastava, Dynamic Gaits and Control in Flexible Body Quadruped Robot, the 1st International and 16th National Conference on Machines and Mechanisms (iNaCoMM2013), (Dec, 18-20, 2013, IIT Roorkee), 2013.

[32] J. Szrek, and P. Wojtowicz, Idea of wheellegged robot and its control system design, Buletin of the polish academy of sciences technical sciences, $58,2010$.

[33] K. Izumi et al., Behavior Selection Based Navigation and Obstacle Avoidance Approach Using Visual and Ultrasonic Sensory Information for Quadruped Robots, International Journal of Advanced Robotic Systems, 5, 379, 2008.

[34] Y. Zhao, F. Gao, and Y. Yin, Obstacle Avoidance and Terrain Identification for a Hexapod Robot. Research Square, 2020.

[35] F. Michaud et al., AZIMUT, a leg-track-wheel robot, Proceedings 2003 IEEE/RSJ International Conference on Intelligent Robots and Systems, (2003) 3, 2553, 2003.

[36] D. Cui, X. Gao, and W. Guo, Mechanism design and motion ability analysis for wheel/track mobile robot, Advances in Mechanical Engineering, 8, 1, 2016.

[37] N. Babu et al., Novel Hybrid Leg-Track Locomotion Robot and its Stability Analysis Using a Unified Methodology, Procedia Computer Science, 133, 486, 2018. 
[38] F. A. Moreno et al., Automatic Waypoint Generation to Improve Robot Navigation Through Narrow Spaces, Sensors, 20, 240, 2020.

[39] G. Yasuda, and H. Takai, Sensor-based path planning and tracking control scheme for nonholonomic wheeled mobile robots, IFAC conference on Mobile Robot Technology, (2001, Jejudo Island), 2001.

[40] H. T. Nguyen, and H. X. Le, Path planning and Obstacle avoidance approaches for Mobile robot, International Journal of Computer Science Issues, 13, 1694, 2016.

[41] A. De Luca, G. Oriolo, M. Vendittelli, Control of Wheeled Mobile Robots: An Experimental Overview. Lecture Notes in Control and Information Sciences, 270, 181, 2010.

[42] H. Gao et al., Adaptive motion control of wheeled mobile robot with unknown slippage, International Journal of Control, 87, 1513, 2014.

[43] M. Sorour, A. Cherubini, and P. Fraisse, Motion Control for Steerable Wheeled Mobile Manipulation, 2019 European Conference on Mobile Robots (ECMR), (2019, Prague), 1, 2019.

[44] Y. Wang et al., Motion control of a wheeled mobile robot using digital acceleration control method, International Journal of Innovative Computing, Information and Control, 9, 387, 2013.

[45] B. Kucaturk, Motion control of wheeled mobile robot, Interdisciplinary Description of Complex Systems, 13, 41, 2015.

[46] K. Iagnemma, S. Shimoda, and Z. Shiller, NearOptimal Navigation of High Speed Mobile Robots on Uneven Terrain, IEEE/RSJ Int. Conf. Intell. Robots Syst. (IROS), 4098, 2008.

[47] J. Laval, L. Fabresse, and N. Bouraqadi, A methodology for testing mobile autonomous robots, 2013 IEEE/RSJ International Conference on Intelligent Robots and Systems, (2013, Tokyo), 1842, 2013.

[48] G. Gao, Q. Qin, and S. Chen, Turning control of a mobile robot for greenhouse spraying based on dynamic sliding mode control, International Journal of Advanced Robotic Systems, 1, 2017.

[49] C. Koc et al., Body Lift and Drag for a Legged Millirobot in Compliant Beam Environment, 2019 International Conference on Robotics and Automation (ICRA), (2019, Montreal), 3108, 2019.

[50] B. F. V. Perez, and P. T. Aquino, A body lifting mechanism for an autonomous service robot, II Brazilian Humanoid Robot Workshop and III Brazilian Workshop on Service Robotics, 47, 2019. [51] X. Jin et al., Four-cable-driven parallel robot, 2013 13th International Conference on Control, Automation and Systems (ICCAS 2013), (October, 20-23, 2013, Gwangju), 2013.
[52] R. A. Tabile et al., Design of the mechatronic architecture of an agricultural mobile robot, 5th IFAC Symposium on Mechatronic Systems, (Sept 13-15, 2010, Cambridge), 717, 2010.

[53] M. Görner, A. Chilian, H. Hirschmüller, Towards an Autonomous Walking Robot for Planetary Surfaces, i-SAIRAS 2010, (August 29September 1, 2010, Sapporo), 170, 2010.

[54] F. Roure et al., GRAPE: Ground Robot for vineyard Monitoring and Protection, ROBOT 2017: Third Iberian Robotics Conference, Advances in Intelligent Systems and Computing, vol. 693, 249, 2017.

[55] C. R. Gil, H. Calvo, and H. Sossa, Learning an Efficient Gait Cycle of a Biped Robot Based on Reinforcement Learning and Artificial Neural Networks, Appl. Sci., 9, 502, 2019.

[56] E. Halbach, Multi-Robot Hillside Excavation Strategies for Mars Settlement Construction, 47th International Conference on Environmental Systems, (16-20 July 2017, Charleston), 2017.

[57] Y. Shin et al., Autonomous Navigation of a Surveillance Robot in Harsh Outdoor Road Environments, Advances in Mechanical Engineering, 2013, 2013.

[58] S. Palazzo et al., Domain Adaptation for Outdoor Robot Traversability Estimation from RGB data with Safety-Preserving Loss, 2020 IEEE/RSJ International Conference on Intelligent Robots and Systems (IROS), (October 25-29, 2020, Las Vegas), 10014, 2020.

[59] C. Wang et al., Safe and Robust Mobile Robot Navigation in Uneven Indoor Environments, Sensors, 19, 2993, 2019.

[60] P. J. Durst et al., The Need for High-Fidelity Robotics Sensor Models, Journal of Robotics, 2011, 2011.

[61] Y. $\mathrm{Zu}$ et al., SURF-BRISK-Based Image Infilling Method for Terrain Classification of a Legged Robot, Appl. Sci., 9, 1779, 2019.

[62] M. Lacagnina et al., Modelling and Simulation of Multibody Mobile Robot for Volcanic Environment Explorations, Intl. Conference on Intelligent Robots and Systems, (October 2002, Lausanne), IEEE, 2002.

[63] H. Jiang et al., Lateral Stability of a Mobile Robot Utilizing an Active Adjustable Suspension, Appl. Sci., 9, 4410, 2019.

[64] Z. Jia, W. Smith, and H. Peng, Terramechanicsbased wheel-terrain interaction model and its applications to off-road wheeled mobile robots, Robotica, 30, 491, 2012.

[65] Y. Bai, L. Sun, and M. Zhang, Terramechanics Modeling and Grouser Optimization for Multistage Adaptive Lateral Deformation Tracked Robot, IEEE Acess, 8, 171380, 2020. 
[66] L. Ding et al., Terramechanics-based HighFidelity Dynamics Simulation for Wheeled Mobile Robot on Deformable Rough Terrain, 2010 IEEE International Conference on Robotics and Automation, (2010, Anchorage), 4922, 2010.

[67] K. Takaya et al., Simulation Environment for Mobile Robots Testing Using ROS and Gazebo, 2016 20th International Conference on System Theory, Control and Computing (ICSTCC), (October 13-15, Sinaia), 96, 2016.

[68] G. Reina et al., Vision-based estimation of slip angle for mobile robots and planetary rovers, 2008 IEEE International Conference on Robotics and Automation, (2008, Pasadena), 486, 2008.

[69] L. Lenain et al., Mixed kinematic and dynamic sideslip angle observer for accurate control of fast off-road mobile robots, Journal of Filed Robotics, 27, 181, 2010.

[70] L. Cheng et al., Positioning and navigation of mobile robot with asynchronous fusion of binocular vision system and inertial navigation system, International Journal of Advanced Robotic Systems, $1,2017$.

[71] N. Ganganath, and H. Leung, Mobile robot localization using odometry and kinect sensor, 2012 IEEE International Conference on Emerging Signal Processing Applications, (2012, Las Vegas), 91, 2012.

[72] J. A. M. Zaki et al., Mobile robot positioning using odometry and ultrasonic sensor, Journal of Cybernetics and Informatics, 13, 40, 2012.

[73] G. Atali et al., Localization of Mobile Robot using Odometry, Camera Images and Extended Kalman Filter, Acta Physica Polonica A, 134, 204, 2018.

[74] G. Antonelli et al., Simultaneous Calibration of Odometry and Camera for a Differential Drive Mobile Robot, 2010 IEEE International Conference on Robotics and Automation, (May 3-8, 2010, Alaska), IEEE, 5417, 2010.

[75] T. D. Larsen et al., Design of Kalman Filters for Mobile Robots; Evaluation of the Kinematic and Odometric Approach, the 1999 IEEE International Conference on Control Applications, (August - 2227, 1999, Hawai), IEEE, 1021, 1999.

[76] J. Zolghadr, and Y. Cai, Locating a two-wheeled robot using Extended Kalman Filter, Tehnički vjesnik 22, 6, 1481, 2015.

[77] F. Kong et al., Mobile Robot Localization Based on Extended Kalman Filter, Proceedings of the 6th World Congress on Intelligent Control and Automation, (June 21 - 23, 2006, Dalian), 9242, 2006.
[78] L. Aguiar et al., Kalman filtering for differential drive robots tracking, XIII Simp'osio Brasileiro de Automa, c ao Inteligente, (October 1-4, 2017, Porto Alegre, 1520, 2017.

[79] H. Ahmad, and T. Namerikawa, Extended Kalman filter-based mobile robot localization with intermittent measurements, Systems Science \& Control Engineering, 1, 113, 2013.

[80] J. Raible, M. Blaich, and O. Bittel, Differential GPS supported navigation for a mobile robot, IFAC Proceedings Volumes, 43, 318, 2010.

[81] V. J. G. Villela et al., A wheeled mobile robot with obstacle avoidance capability, Ingenieria Mecanica Tecnologia Y Desarrollo, 1, 159, 2004.

[82] T. Mylvaganama, and M. Sassano, Autonomous collision avoidance for wheeled mobile robots using a differential game approach, European Journal of Control, 40,53, 2018.

[83] A. Diaz-Calderon, and A. Kelly, On-Line Stability Margin and Attitude Estimation for Dynamic Articulating Mobile Robots, The International Journal of Robotics Research, 24, 845, 2005.

[84] L. Adouane, A. Benzerrouk, and P. Martinet, Mobile Robot Navigation in Cluttered Environment using Reactive Elliptic Trajectories, the 18th World Congress The International Federation of Automatic Control, (August 28 - September 2, 2011, Milano ), 13801, 2011.

[85] T. T. Hoang et al., Proposal of Algorithms for Navigation and Obstacles Avoidance of Autonomous Mobile Robot, 2013 IEEE 8th Conference on Industrial Electronics and Applications (ICIEA), (2013, Melbourne), 1308, 2013.

[86] S. C.Yun, S. Parasuraman, and V. Ganapathy, Dynamic Path Planning Algorithm in Mobile Robot Navigation, 2011 IEEE Symposium on Industrial Electronics and Applications (ISIEA2011), (September 25-28, 2011, Langkawi), 364, 2011.

[87] K. E. Bekris, A. A. Argyros, and L. E. Kavraki, Angle-Based Methods for Mobile Robot Navigation: Reaching the Entire Plane, the 2004 IEEE International Conference on Robotics \& Automation, ( April, 2004, Los Angeles), 2373, 2004.

[88] M. Sauer et al., Remote control of mobile robots in low bandwidth environments, the Second International Conference on Informatics in Control, Automation and Robotics, 163, 2005.

[89] T. E. C. Keith (Ed.), The 1992 Eruptions of Crater Peak Vent Mount Spurr Volcano, Alaska, United States Government Printing Office, Washington DC, 1, 1995. 
[90] M. E. Qazizada, and E. Pivarčiová, Mobile robot controlling possibilities of inertial navigation system, International Conference on Manufacturing Engineering and Materials, ICMEM 2016, (6-10 June 2016, Nový Smokovec), vol 149 (Amsterdam: NorthHolland/American Elsevier), 404, 2016.
[91] B. S. Cho et al., A dead reckoning localization system for mobile robots using inertial sensors and wheel revolution encoding, Journal of Mechanical Science and Technology, 25, 2907, 2011.

[92] S. Brance et al., Geological evolution of Mount Etna volcano (Italy) from earliest products until the first central volcanism (between 500 and $100 \mathrm{ka}$ ago) inferred from geochronological and stratigraphic data, Int. J. Earth Sci., 97, 135, 2008. 